\title{
Clinical, Therapeutic and Evolutive Aspects of Patients with Hemophilia in the Surgical Resuscitation Care Unit of Joseph Ravoahangy Andrianavalona JRA Hospital Antananarivo
}

\author{
Tamby Rakoto Alson Andrianjafiarinoa, \\ Tantely Anjarahaingo Voahangiarivola Randriamandrato, Andriamiadana Luc Rakotovao, \\ Aimée Olivat Rakoto Alson*, Andriambelo Tovohery Rajaonera
}

JRA Hospital, Antananarivo, Madagascar

Email: *olivatrakoto@yahoo.fr

How to cite this paper: Andrianjafiarinoa, T.R.A., Randriamandrato, T.A.V., Rakotovao, A.L., Alson, A.O.R. and Rajaonera, A.T. (2019) Clinical, Therapeutic and Evolutive Aspects of Patients with Hemophilia in the Surgical Resuscitation Care Unit of Joseph Ravoahangy Andrianavalona JRA Hospital Antananarivo. Case Reports in Clinical Medicine, 8, 9-20.

https://doi.org/10.4236/crcm.2019.81002

Received: December 3, 2018

Accepted: January 13, 2019

Published: January 16, 2019

Copyright $\odot 2019$ by author(s) and Scientific Research Publishing Inc. This work is licensed under the Creative Commons Attribution International License (CC BY 4.0).

http://creativecommons.org/licenses/by/4.0/

\section{(c) (i) Open Access}

\begin{abstract}
Background: Hemophilia, a constitutional bleeding disease, has always been present in Madagascar considering children who died after bleeding circumcision, as reported in the family history of the diagnosed patients. Hemophilia is serious because of the potentially fatal risk of hemorrhage. The aim of this study was to evaluate the clinical, outcome and therapeutic aspects of inpatients with hemophilia in the Surgical Resuscitation Unit of JRA Hospital in Antananarivo. Methodology: A descriptive and observational study was led about patients with hemophilia cared in the Surgical Resuscitation Unit from January 2011 to March 2018, studying age, type and severity of hemophilia, reason and duration of hospitalization, treatment instituted and outcome of patients. Results and comments: Thirty-six hemophiliacs (0.2\%) were enrolled. The mean age was 9.52 years old; $52.78 \%$ were with hemophilia B and $47.22 \%$ with hemophilia A, mainly severe. Clinical manifestations were muscle hematomas $(25.71 \%)$, gum bleeding (14\%), epistaxis $(14.28 \%)$, gastrointestinal bleeding (11.42\%), intracranial hemorrhage (11.42\%), post circumcision bleeding (11.42\%), hematuria, intraperitoneal hematomas and hemarthrosis. Treatment was based on factor concentrate substitution when available. The length of stay ranged from one to thirty days. The evolution was favorable except for two deaths related to delayed management of intracranial hemorrhage. Three patients with hemophilia A developed inhibitors. The results showed that throughout these years of study, a change in management was noted alongside. Conclusion: Hemophilia cases requiring hospitalization were managed in surgical resuscitation unit. The evolution was
\end{abstract}


mainly related to the availability of clotting factor concentrates in coagulation factors, the delay in taking care of the patients and the presence of specialized staff.

\section{Keywords}

Hemophilia, Bleeding, Hematoma, Factor Concentrate, Inhibitor

\section{Introduction}

Blood has always been linked to life; one cannot live without blood. Blood losses are not only provoked; there are those related to blood abnormalities. Hemophilia is one of them, a constitutional hemorrhagic disease, serious due to risk of fatal hemorrhage, genetically transmitted in a recessive mode linked to the $\mathrm{X}$ chromosome.

This genetic abnormality, resulting in a deficiency of a coagulation factor VIII for hemophilia A or coagulation factor IX for hemophilia B, has not spared Madagascar [1].

It affects without exception all countries in the world, developing or developed countries, but the level of understanding, care and evolution vary from country to country.

Its prevalence is not completely known in Africa for several reasons: rarity of the disease, high cost of its management, insufficient number of specialists in hematology and absence of adequate laboratories for the biological diagnosis of this disease. It is, however, established that hemophilia is a ubiquitous condition with an annual incidence of 1 in 5000 male births and an estimated population prevalence of 1 in 10,000 to 12,000 regardless of race or geographical area [2] [3]. It is the most common serious hemorrhagic disease in the world. The incidence of hemophilia A is 1 per 5000 births of male children while that of hemophilia B is 1 in 30,000 [2].

Hemophilia has always been present in Madagascar if we consider children who died after bleeding circumcision, as reported in the family history of the diagnosed patients, although, the 125 currently registered patients amount to $5 \%$ of the estimated number of Malagasy patient with hemophilia ( $\mathrm{PwH})$.

Cases of de novo hemophilia were found in the absence of similar hemorrhagic situations in the family. These constitute most of Malagasy $\mathrm{PwH} \mathrm{B}$, which are curiously higher in frequency compared to the theoretical world data.

The $\mathrm{PwH}$ is a person who lives first in a society. Their immediate neighborhoods, which may be their family, playmates or classmates, are primarily confronted with the hemorrhagic accidents that may occur. They may also be surrounded by members of the society of hemophilia. But they will be routed when needed directly to the nearest health center and especially to the responsible for their illness if they are already known. 
The objective of this study was to evaluate the clinical, therapeutic approach and outcome of $\mathrm{PwH}$ admitted to the Surgical Resuscitation Unit, responsible for caring of $\mathrm{PwH}$ requiring hospitalization in Antananarivo Madagascar.

\section{Patients and Method}

The Surgical Resuscitation Unit is part of the medical framework for treating hemophilia in Antananarivo Madagascar by treating patients with hemophilia requiring hospitalization.

This descriptive and observational study of all patients with hemophilia admitted to the Surgical Resuscitation Department was led from January 2011 to March 2018.

All hemophilia patients requiring hospitalization and admitted to the Surgical Resuscitation Unit during the period of study were included. Those with other types of congenital bleeding disorders were immediately dismissed.

The studied parameters were the age of the patient, the type and the severity of the disease, the reason for hospitalization, the elements of the treatment and the evolution.

The age of the hemophiliac patient at the time of admission to the hospital was recorded in years.

The type of hemophilia A (factor VIII deficiency) or B (factor IX deficiency) as well as the severity can be found, among other things, on the hemophilia card of each patient. This card was given to each hemophilia patient diagnosed from the year 2015. For patients who had not yet had a card at their admission (before 2015) or who had forgotten it, the type and severity of hemophilia were transmitted by the Hemophilia Treatment Center of JRA Hospital which holds the registry of hemophilia in Madagascar.

The characteristics and location of the hemorrhagic syndrome motivated the admission of the patients to the surgical resuscitation unit. They may be patients referred by the Hemophilia Treatment Center or patients admitted directly to the Resuscitation Department.

The duration of hospitalization was counted from the day of admission for the reason of hospitalization to the actual day of discharge.

Treatment was based on substitution therapy, with or without adjuvant therapy. The study considered the use of fresh frozen plasma (FFP) transfusion, the use of other hemostatic drugs, and access to the specific antihemophilic factor concentrate.

The study noted the evolution of the bleeding syndrome after the treatment undertaken as well as the state of the patient during his hospitalization, the favorable course, the presence of complications or the patient's death.

Data were collected and analyzed in Excel 2013. The averages were calculated with a $95 \%$ confidence interval. A value of $p<0.05$ was considered significant, using the chi-square test.

The study was careful to keep confidential the identity of the patients as well as all the data concerning them. 


\section{Results and Comments}

Of the 14,658 patients hospitalized in the Surgical Resuscitation Unit during the study period, $36(0.27 \%)$ obviously male patients were with hemophilia.

The average age of inpatients was 9.59 years old with extremes of 2 and 43 years old.

The median age was between 4 and 15 years old with the maximum number of patients $(\mathrm{n}=17,47 \%), 13$ patients $(36 \%)$ were over 15 years old and $6(17 \%)$ were less than 3 years old (Figure 1).

According to the type of hemophilia and the severity of the disease, 19 (52.78\%) were patients with hemophilia B and 17 (47.22\%) with hemophilia A, the majority of patients had severe hemophilia i.e. with a factor level $<1 \%, 15$ out of 19 hemophilia B and 12 out of 17 hemophilia A. Moderate hemophilia defined as factor level between $1 \%$ and $5 \%$ accounted for $25 \%$ of patients $(n=9)$. There were no cases of mild or minor hemophilia (factor $>5 \%$ ) (Figure 2).

The reasons for hospitalization were smooth muscle hematoma for 9 patients (25.71\%), gum bleeding and epistaxis respectively for 5 patients (14.28\%), gastro intestinal bleeding for 4 patients $11.42 \%$, intracranial hemorrhage for 4 patients (11.42\%), 4 patients (11.42\%) had bleeding after circumcision, two patients (5.71\%) with hematuria, one with hemarthrosis, one with hemoperitoneum and one with obnubilation (Table 1).

Of the hemophilia patients, $31.42 \%$ were given replacement therapy with clotting factor concentrate.

Regarding replacement factor, 1048 IU was the average amount of factor VIII for patients with hemophilia A. For those with hemophilia B, the amount of average factor IX injected was 1277 IU. In addition to coagulation factor concentrate, $45.71 \%$ of patients received transfusion of FFP. Tranexamic acid was the antifibrinolytic molecule used in patients with hemophilia included in the study, with $10 \mathrm{mg} / \mathrm{kg}$ every 8 hours in intravenous route, apart from the patient with hematuria where antifibrinolytic agent was not indicated.

Seeking for inhibitors was specified when persistence of the bleeding syndrome despite the substitutive treatment. Three patients with severe hemophilia A were confirmed having developed inhibitors (8.33\%). An 8-year-old patient was admitted for hemarthrosis localized in the right knee. The search for inhibitors in this patient was performed after 3 days of factor replacement therapy in response to a poor clinical response. Another one, 19 years old, was first admitted in 2015 for iliopsoas hematoma and in 2017 for epistaxis. Factor assay in this patient was performed after 6 days of factor replacement therapy with poor clinical response to treatment. The third, a 6-year-old patient, was exposed to replacement therapy due to the management of a traumatic fracture of the forearm. The inhibitor assay was performed at 7 days of factor replacement therapy (Figure 3).

Mean hospital stay was 8.5 days with extremes of 1 and 30 days.

Most patients $(n=27,74.28 \%)$ were discharged directly after a favorable course of the bleeding syndrome. 
Table 1. Causes for hospitalization.

\begin{tabular}{|c|c|}
\hline Causes for hospitalization & Frequency \\
\hline Rectal bleeding & 1 \\
\hline Lodge syndrome on closed radius fracture & 1 \\
\hline Cranial injury with obnubilation & 1 \\
\hline Hemoperitoneum & 1 \\
\hline Post circumcision hemorrhage & 4 \\
\hline Hemarthrosis & 1 \\
\hline Hematuria & 2 \\
\hline Hematemesis post tonsillectomy & 1 \\
\hline Gastrointestinal bleeding & 2 \\
\hline Gum bleeding & 5 \\
\hline Epistaxis & 5 \\
\hline Epidural hematoma & 1 \\
\hline Subdural hematoma & 2 \\
\hline Hematoma and brainstem compression & 1 \\
\hline Iliopsoas hematoma & 8 \\
\hline Total & 36 \\
\hline
\end{tabular}

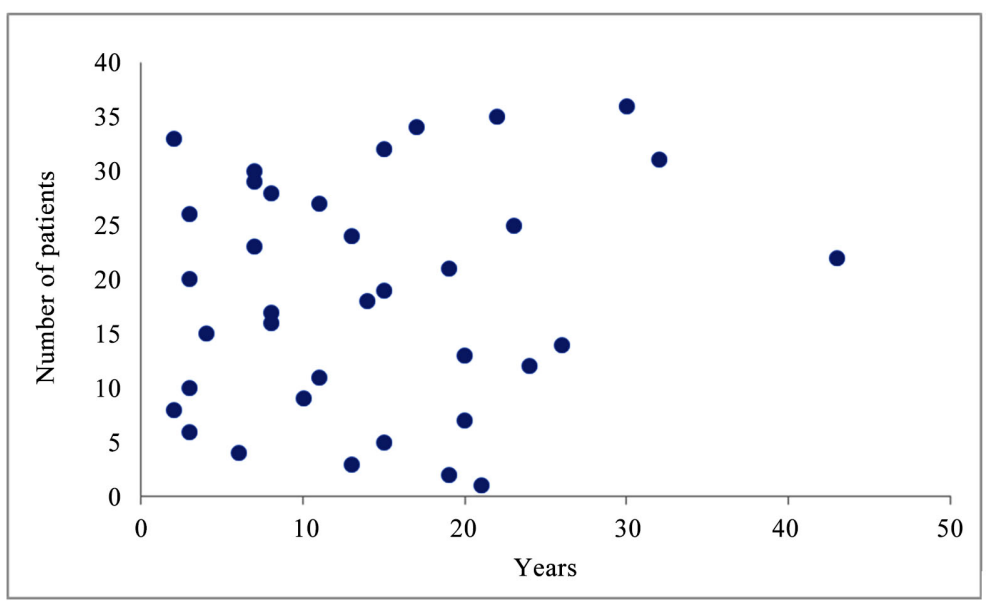

Figure 1. Age of inpatients with hemophilia.

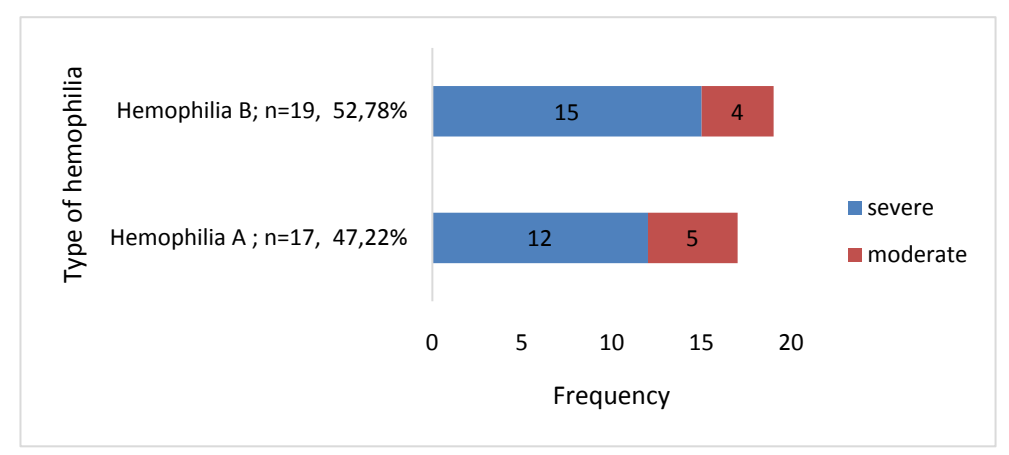

Figure 2. Type and severity of hemophilia. 


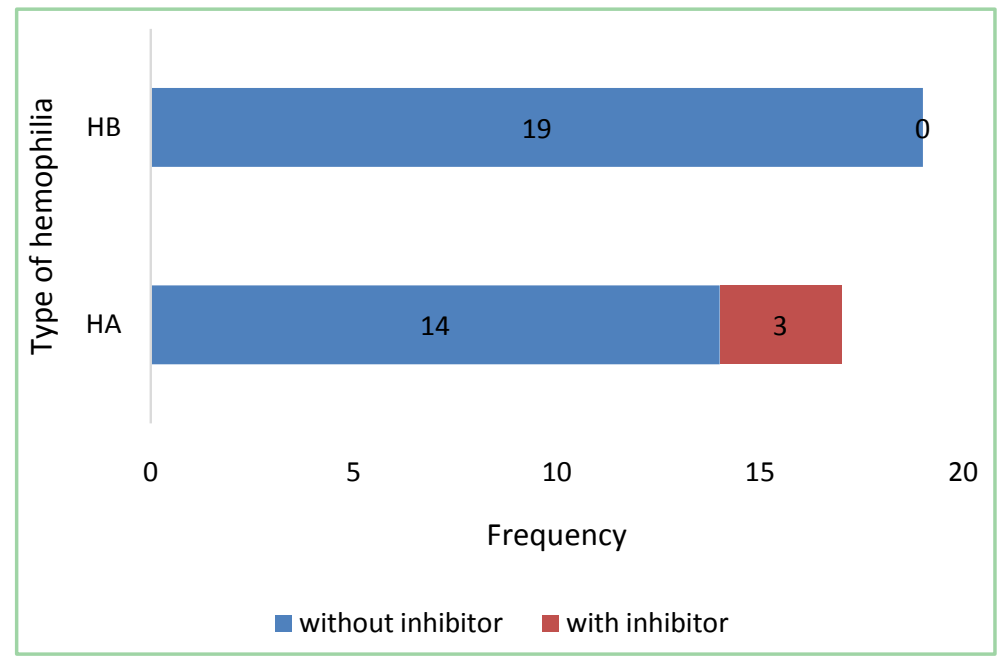

Figure 3. Frequency of inhibitor development.

Seven patients (20\%) were moved to other departments, particularly in the Visceral Surgery one for surgical wound monitoring.

Two patients $(5.71 \%)$ unfortunately did not survive: two patients with post-traumatic intracranial hemorrhage, who arrived at the hospital only 48 hours later in a coma state.

Regarding the length of hospital stay, patients with hemophilia A had significantly a long duration of stay (10 days) compared to patients with hemophilia B (5 days) with a p-value $<0.0001$ (Figure 4 ).

Patients with hemophilia A required more FFP transfusion ( 6 bags) compared to those with hemophilia B patients ( 3 bags) with a p-value $<0.0001$ (Figure 5 ).

Clinical manifestations analysis according to the type of the hemophilia and the age did not allow to note any significant difference on the clinical aspects and on the outcome with a p-value $>0.05$ (Table 2).

The number of patients who developed inhibitors was 3 out of 17 patients with hemophilia A whereas none of the 19 hemophiliac patients B had developed inhibitors but the difference was not significant $(p>0.05)$.

However, a significant difference was noted in the amount of FFP transfusion and the length of hospital stay.

The purpose of this study was to describe the clinical, therapeutic and progressive aspects of hemophilia patients who required hospitalization. The Surgical Resuscitation unit of JRA Hospital is in charge of taking care of these patients. Although they represent only a small part of the patients admitted to intensive care, they nevertheless constitute a heavy burden due to seriousness of complications of hemophilia.

The number of patients with hemophilia $(\mathrm{PwH})$ in the surgical resuscitation department was very low compared to the volume of activities of this unit. A study led by Tutus F et al. in 2012 in Brussels found the same result with only $0.05 \%$ of patients admitted to emergency departments being with hemophilia [4]. 
Resuscitation Unit main objective is the management of patients whose vital prognosis is engaged [5]. $\mathrm{PwH}$ are included in life-threatening patients with hemorrhagic episodes, particularly for high-risk hemorrhagic sites.

The selection of patients to be admitted into intensive care is based on many criteria such as the severity of the pathology, the state of the patient and the background [6].

$\mathrm{PwH}$ may not only have various clinical manifestations related to their bleeding disorder, but also medical or surgical problems other than hemophilia bleeding, which should be managed appropriately [4].

Table 2. Comparative analysis of variables according to the type of hemophilia.

\begin{tabular}{|c|c|c|c|}
\hline Variables & $\begin{array}{c}\text { Hemophilia A } \\
(\mathrm{N}=17)\end{array}$ & $\begin{array}{l}\text { Hemophilia B } \\
\quad(\mathrm{N}=19)\end{array}$ & $\mathrm{p}$-value \\
\hline Meanage & $15.94 \mathrm{ys}$ & $12.00 \mathrm{ys}$ & 0.2 \\
\hline \multicolumn{4}{|l|}{ Severity } \\
\hline - Moderate & 5 & 4 & \multirow{2}{*}{0.87} \\
\hline - Severe & 12 & 15 & \\
\hline \multicolumn{4}{|l|}{ Causes for admission } \\
\hline - Gastrointestinal bleeding & 1 & 3 & \\
\hline - Gumbleeding & 2 & 3 & \\
\hline - Post circumcisionbleeding & 1 & 3 & \\
\hline - Muscle hematoma & 6 & 3 & \\
\hline - Intracranialbleeding & 1 & 3 & \\
\hline - Hemarthrosis & 1 & 0 & \\
\hline - Hemoperitoneum & 1 & 0 & 0.88 \\
\hline - Hematuria & 1 & 1 & \\
\hline - Epistaxis & 4 & 1 & \\
\hline Length of stay & 10 days & 5 days & $<0.0001$ \\
\hline \multicolumn{4}{|l|}{ Outcome } \\
\hline - Favorable & 15 & 15 & \\
\hline - Death & 1 & 1 & NS \\
\hline
\end{tabular}

Length of stay (days)

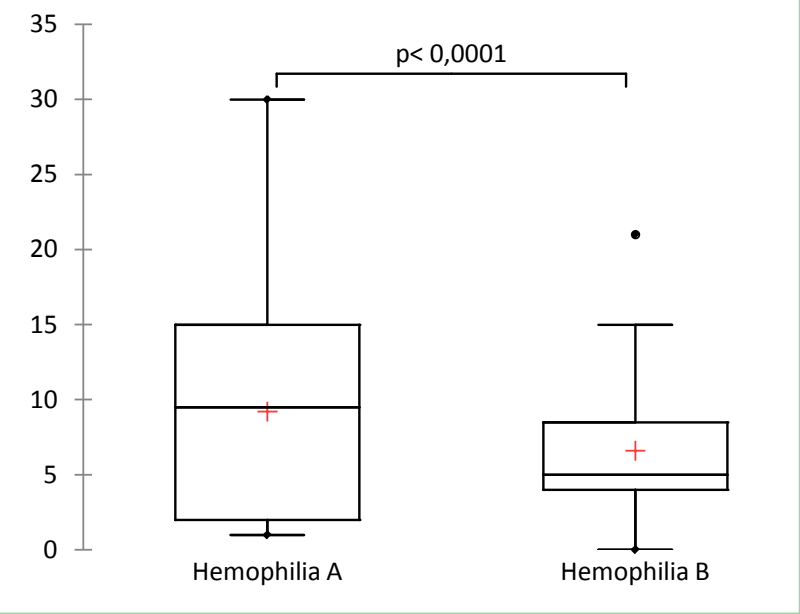

Figure 4. Length of hospital stay. 


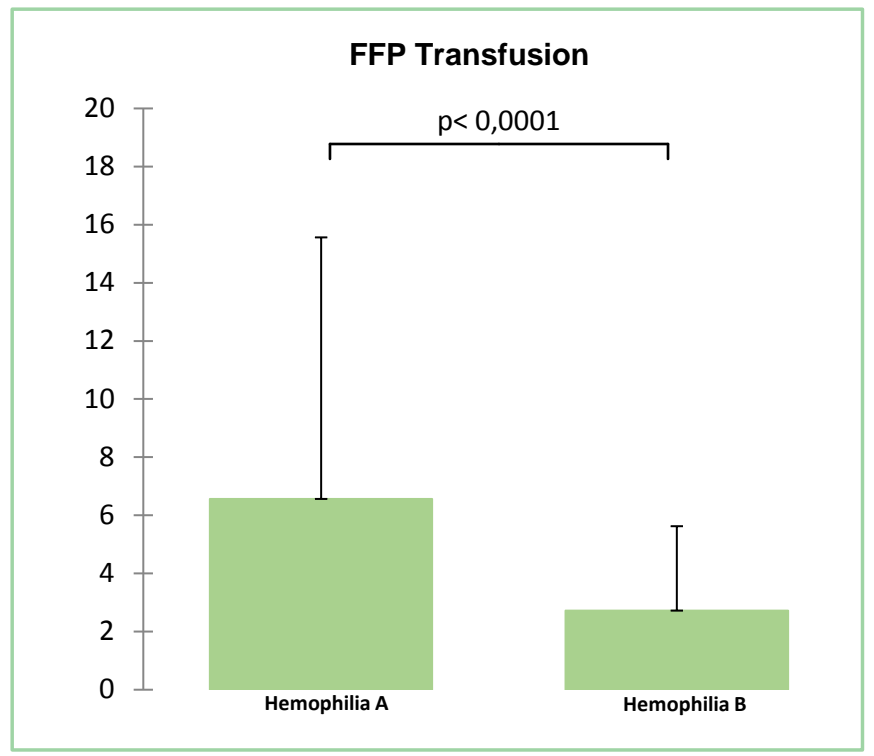

Figure 5. FFP transfusion according to type of hemophilia.

All of these reasons including serious conditions either because of bleeding location, because of their complication, or because of their unpredictable evolution, justify the presence of $\mathrm{PwH}$ in intensive care unit.

Moreover, it is interesting to note that the frequency of hemophilia B in Madagascar is much higher than the average described in the literature, especially Diop S et al. in Senegal report an incidence of $90.7 \%$ for hemophilia A and 9.2\% for hemophilia B [3] and Mason et al. in Australia, 81.2\% for hemophilia A and 18.7\% for hemophilia B [7].

The most common manifestation found in this study was muscle hematoma with a predominance of localization in the iliopsoas muscle, followed by gum bleeding and epistaxis.

Management of muscle hematoma requires for the most part a surgical treatment [8]. Given the high bleeding risk in $\mathrm{PwH}$ and the lack of adequate platform in other units for the management of a possible abundant hemorrhage, the choice of the surgical resuscitation unit was adapted to the situation.

This predominance of muscle localization is also found in other studies as it was described by Fernandez-Palazzi et al. in 1996 [9], Ashrani et al. in 2003. [10] and confirmed by a previous study by Fety in 2016 concerning iliopsoas hematoma in Malagasy $\mathrm{PwH}$ [11].

Epistaxis and gum bleeding are certainly not dramatic clinical manifestations, but their evolution is still unpredictable especially in case of severe hemophilia or development of inhibitors [12].

Although osteoarticular complications of hemophilia do not represent a majority among the clinical manifestations in resuscitation unit in this study, they remain nonetheless dangerous. Indeed, they can lead to disabling sequelae seriously affecting the quality of life of $\mathrm{PwH}$ [8]. This is why fast and effective care as well asclose supervision must be implemented. According to Vanderhave et 
al., early hemarthrosis should be managed aggressively with a concentrate of aspiration and coagulation factor until the joint examination is normal [8]. Hemarthrosis is not a reason for hospitalization in intensive care. The only case admitted and found in this study concerned a hemarthrosis greatly invalidated, highly painful and resistant to the treatment occurring in a patient with development of inhibitors, after exposure to a substitutive concentrate factor, explaining the persistence and worsening of clinical manifestations.

Intracranial hemorrhage is in itself a life-threatening condition [13], leading $\mathrm{PwH}$ to the surgical resuscitation unit. The Glasgow score is one of the criteria for admission to the Surgical Resuscitation Department for neurosurgery. This score is the reference for assessing the coma depth of a patient over the age of 5 , supplemented by the Liege score, which evaluates reflexes of the brainstem [14].

Patients with a Glasgow score of 8 or less are admitted to the Surgical Resuscitation Unit. Some exceptions, however, are noteworthy depending on the patient's state and context. Hemophilia is one of them because of the sometimes rapid and unpredictable evolution of neurological signs. The case of a $\mathrm{PwH} \mathrm{B}$ hospitalized in the Department of Surgical Resuscitation was the subject of a study in 2012 to illustrate this situation: he started from a Glasgow score of 12 to evolve in a few hours to a very huge extra-dural hematoma [15].

Hemoperitoneum also motivated admission of $\mathrm{PwH}$ in this study. According to Jones JJ, it is a major mortality factor in $\mathrm{PwH} \mathrm{[16].} \mathrm{This} \mathrm{necessarily} \mathrm{requires}$ hospitalization in a surgical resuscitation unit, not only because of its severity but also the very likely possibility of surgical evacuation.

$\mathrm{PwH}$ with gastrointestinal bleeding (11.4\%), such as melena, hematemesis or rectal bleeding, were admitted to the Surgical Resuscitation Unit. Gastrointestinal bleeding can unpredictably progress, potentially leading to a life-threatening situation [17].

During this study, it was noted that gastrointestinal bleeding was a common reason for hospitalization in the Resuscitation Unit for non-hemophiliac patients. The literature indicates that $\mathrm{PwH}$ exercise it 5 to 10 times more frequently than a non-haemophiliac population not exposed to non-steroidal anti-inflammatory drugs [18].

Three patients were hospitalized for post circumcision bleeding. Circumcision is part of the culture in Madagascar. Its practice exposes patients with hemophilia to a high risk of perioperative and postoperative bleeding, especially in developing countries where the disease is still poorly understood by the population and where financial means are limited [19]. Many Malagasy PwH have a family history of post-circumcisional deaths, due to an abundant post operate bleeding, during a traditional way for most of the time. It is only after one or more deaths that investigations are started to establish a diagnosis for the others members of the family. Worldwide, the incidence of bleeding complications in some countries during circumcision is still significantly elevated in known hemophiliacs. For example, Nigeria has a frequency of 52\% [20], and for Morocco a frequency 
of $41 \%$ [19]. In Turkey, however, one study found a frequency of $6 \%$, due to the use of fibrin glue in this country when practicing circumcision of hemophiliac patients [21].

Concerning inhibitors, it was reported that about $20 \%$ to $30 \%$ of severe hemophiliacs develop an anti-FVIII antibody as a result of treatment. On the other hand, the risk is lower for PwH B [17]. In this study, all of the patients who developed inhibitors were PwHA severe, no $\mathrm{PwH} \mathrm{B}$ was found during this study coinciding with the literature [22].

Some $\mathrm{PwH}$ were not included because their records were lost. This is essentially the limit to this study.

The results showed that throughout these years of study, a change in management was noted alongside. The awareness of this disease has been enhanced and the availability of clotting factor concentrates effective since 2016 thanks to WFH Humanitarian Aid program.

\section{Conclusions}

The knowledge of hemophilia by healthcare professionals in Madagascar has significantly improved the conditions of care of patients with hemophilia. The results observed in this study show a good evolution of this care; advances have been noted but much remains to be done.

The evolution was mainly related to the availability of concentrates in coagulation factors, the time taken to treat patients and the existence of specialized healthcare professional dedicated to patients with hemophilia.

The development of inhibitors, however, hampers the management of hemophilia, a topic of current research in the hemophilia scientific community.

\section{Conflicts of Interest}

The authors declare no conflicts of interest regarding the publication of this paper.

\section{References}

[1] RakotoAlson, A.O., Raherimandimby, H., Rajaofera, T., Rakotovao, A.L., Herisoa, F.R. and Rasamindrakotroka, A. (2009) Mise au point sur la prise en charge de l'hémophilie à Madagascar. $R A R M U, 1, \mathrm{~S} 1-\mathrm{S} 6$.

[2] Biron, C. and Schved, J.F. (2005) Hémophilie in Hématologie clinique et biologique. 2nd Edition, Arnette, Marseille, 49-34.

[3] Diop, S., Seck, M., Sy-Bah, D., Faye, B.F., Sow-Ndoye, A., Gueye, Y.B., Senghor, A.B., Sall-Fall, A., Toure-Fall, A.O., Dièye, T.N., Thiam, D. and Diakhate, L. (2014) Implementing Haemophilia Care in Senegal, West Africa. Haemophilia, 20, 73-77. https://doi.org/10.1111/hae.12249

[4] Tutus, C., Thys, F. and Herman, C. (2012) Prise en charge de l'hémophilie en salle d'urgence. Annales Françaises de Medecine D’urgence, 2, 256-264.

https://doi.org/10.1007/s13341-012-0189-6

[5] Fourrier, F., Boiteau, R., Charbonneau, P., Drault, J.N., Dray, S., Farkas, J.C., Leclerc, F., Misset, B., Rigaud, J.P., Saulnier, F., Soury-Lavergne, A., Thévenin, D. and 
Wolff, M. (2012) 300 Recommendations and Guidelines on Structural and Organizational Requirements for Intensive Care. Réanimation, 21, S523-S539. https://doi.org/10.1007/s13546-012-0510-9

[6] Puybasset, L. (2010) Enjeux éthiques en réanimation. Première Edition, Springer Verlag France, Paris. https://doi.org/10.1007/978-2-287-99072-4

[7] Mason, J.A., Parikh, S., Tran, H., Rowell, J. and McRae, S. (2018) Australian Multicentre Study of Current Real-World Prophylaxis Practice in Severe and Moderate Haemophilia A and B. Haemophilia, 24, 253-260. https://doi.org/10.1111/hae.13375

[8] Vanderhave, K.L., Caird, M.S., Hake, M., Hensinger, R.N., Urquhart, A.G., Silva, S. and Farley, F.A. (2012) Musculoskeletal Care of the Hemophiliac Patient. The Journal of the American Academy of Orthopaedic Surgeons, 20, 553-563.

[9] Fernandez-Palazzi, F., Hernandez, S.R., De Bosch, N.B. and De Saez, A.R. (1996) Hematomas within the Iliopsoas Muscles in Hemophiliacs Patients: The Latin American Experience. The Journal of the American Academy of Orthopaedic Surgeons, 328, 19-24. https://doi.org/10.1097/00003086-199607000-00005

[10] Ashrani, A.A., Osip, J., Christie, B. and Key, N.S. (2003) Iliopsoashaemorrhage in Patients with Bleeding Disorders experience from One Center. Haemophilia, 9, 721-726. https://doi.org/10.1046/j.1351-8216.2003.00822.x

[11] Fety, A. (2016) Hématome du psoas chez l'hémophile malgache. Thèse, Médecine, Antananarivo, $34 \mathrm{p}$.

[12] Charrier, J.B. (2009) Épistaxis, spécificités en médecine d’urgence. Urgence SAMU de France, 527-33.

[13] bi Gohi, S.I., Pete, Y., Koffi, N., Nda-Koffi, C., Ogondon, B., Kouadio, S., Able, E., and Brouh, Y. (2017) Epidemiological Profile of Craniocerebral Trauma at the Intensive Care Unit of the Bouake University Hospital. Trauma \& Acute Care, 19, 323-327.

[14] Teasdale, G. and Jennett, B. (1974) Assessment of Coma and Impaired Consciousness: A Practical Scale. The Lancet, 2, 81-84. https://doi.org/10.1016/S0140-6736(74)91639-0

[15] RakotoAlson, O.A., Randriamandrato, T. and Rajaonera, T.A. (2012) Cerebral Hemorrhage in a Malagasy with Hemophilia B. Haemophilia, 18, 137-138.

[16] Jones, J.J. and Kitchens, C.S. (1984) Spontaneous Intra-Abdominal Hemorrhage in Hemophilia. Archives of Internal Medicine, 144, 297-300. https://doi.org/10.1001/archinte.1984.00350140105015

[17] Goudemand, J. (2009) Urgences hémorragiques chez l'hémophile. Urgences, 255-273.

[18] Eyster, E.M., Asaad, S.M., Gold, B.D., et al. (2007) Upper Gastrointestinal Bleeding in Haemophiliacs: Incidence and Relation to Use of Non-Steroidal Anti-Inflammatory Drugs. Haemophilia, 13, 279-286. https://doi.org/10.1111/j.1365-2516.2007.01453.x

[19] Nafil, H., Tazi, I. and Mahmal, L. (2013) Circoncision chez les hémophiles A dans la région de Marrakech (Maroc). Médecine et Santé Tropicales, 23, 111-112.

[20] Shittu, O.B. and Shokunbi, W.A. (2001) Circumcision in Haemophiliacs: The Nigerian Experience. Haemophilia, 7, 534-536. https://doi.org/10.1046/j.1365-2516.2001.0537b.x

[21] Yilmaz, D., Akin, M., Ay, Y., et al. (2010) A Single Centre Experience in Circumcision of Haemophilia Patients, Izmir Protocol. Haemophilia, 16, 888-891.

https://doi.org/10.1111/j.1365-2516.2010.02324.x 
[22] Wight, J. and Paisley, S. (2003) The Epidemiology of Inhibitors in Haemophiliaa, Systematic Review. Haemophilia, 9, 418-435.

https://doi.org/10.1046/j.1365-2516.2003.00780.x 